\title{
What a Person Thinks Upon Learning He Has Chosen Differently from Others: \\ Nice Evidence for the Persuasive-Arguments Explanation of Choice Shifts
}

\author{
Eugene BURNSTEIN AND AMIRAM VinOKUR
}

\section{University of Michigan}

Small shifts in choice occur even without discussion, when individuals merely know each other's preference. This appears to support an interpersonal comparison explanation of group induced shifts in choice and to refute explanations based on persuasive argumentation. The present study demonstrates the contrary, that such effects are consistent with the persuasive-arguments formulation and are obtained under particular conditions specified only by the latter theory, to wit: Knowledge of other's choices is assumed to lead a person to think of reasons (arguments) others might have had for their choices-reasons which ordinarily would not come to mind without this knowledge. Such reasoning functions in the same way as persuasive argumentation during group discussion; it causes the person to persuade himself that an alternative course of action now has greater merit than the one he initially preferred. To test this analysis, an experiment was performed in which subjects responded to choice-dilemma items under three different conditions: Following their own choice (I) they learned what several others had chosen and then wrote arguments in support of alternatives given in that same item; (II) they learned what several others had chosen and then wrote arguments in support of alternatives given in a different item; and (III) they received no information about others' choices but merely wrote arguments on that item. As predicted, shifts in choice occurred only if the person knew what others chose and had an opportunity to think about the latter (condition I); they did not occur if an opportunity to think of others' choices was denied (condition II), nor if knowledge of others' choices was withheld (condition III). Content analysis of the arguments subjects produced in conditions I and II completely supported the hypothesis, as did analyses of responses to postexperimental questionnaire which directly asked the subjects about their feelings and thoughts upon learning what others had chosen.

This study is one of a series having to do with, among other things, the relative impact of informational (or cognitive) versus normative (or motivational) processes on the position an individual takes following group discussion. That this is a fundamental problem in the analysis of social influence was recognized at the very beginning of research on behavior in groups. Over $35 \mathrm{yr}$ ago Thorndike (1938a) stressed the point

This research was supported by a Grant from the National Institute of Mental Health (MH-16950-05). 
that discrepancies between the initial opinions and those held following group discussion may be due either (a) ". . . merely to knowing the opinion of the other members of the group, and shifting to conform to it ..." or (b) ". . . to the intellectual give-and-take of discussion..."-a distinction Deutsch and Gerard (1955) later reemphasized in their influential paper. In the present experiment we try to specify how in the absence of normative incentives (say, a desire to avoid the chagrin of disagreement), knowledge of where others stand on an issue can by itself sway a person. More specifically, an attempt is made to demonstrate that the manner in which one thinks or, if you will, argues to himself, about an issue and thus the attitude or preference he subsequently expresses can be guided by such knowledge.

The experimental paradigm for studying group effects on individual preferences has been relatively invariant: initial opinions are compared with those held following discussion (or with the group decision). At the same time a motley assortment of items has been served up for discussion. In addition to the widely used Choice-Dilemma Questionnaire involving the selection of a probability level (Kogan \& Wallach, 1964, Appendix E), revisions in preference have been studied using a wide variety of attitudinal items (Doise, 1969; Gouge \& Fraser, 1972; Moscovici \& Zavalloni, 1969; Myers \& Bishop, 1970, 1971), as well as diverse problems of fact or logic (Barnlund, 1950; Hall, Mouton, \& Blake, 1963; Lorge \& Solomon, 1955; Thomas \& Fink, 1961; Thorndike, 1938a, 1938b). Myers \& Lamm (in press) have thoroughly reviewed this mammoth literature.

Unfortunately the discussion effect has been labeled differently depending on the kind of itcm used. It is perhaps for this reason that there has been a failure to recognize that these shifts in preferences-regardless of the item-are fundamentally similar, tokens of the same type, reflecting a general and pervasive consequence of social discourse (see a model which describes the common underlying process in Vinokur \& Burnstein, 1974). So in more benighted times, changes in probability preferences following discussion were dubbed "risky" or "cautious" shifts. When it dawned that these shifts had little to do with risk or caution, the neutral phrase "choice-shift" was suggested (Pruitt, 1971a, b) and a French researcher, more prudent to begin with, merely said "extremization" (Lambert, 1969, 1971). Changes on standard attitude scales were tagged as cases of "polarization" (Moscovici \& Zavalloni, 1969). Finally, those prosaic scholars who compared individual preand postdiscussion solutions to assorted logical and factual problems simply recorded whether the shift was toward a superior or inferior choice (see reviews by Kelley \& Thibaut, 1969; Steiner, 1972).

Because our purpose is to observe what a person thinks when he knows the preference of others and how such thinking affects his own 
preference, it is unfortunate that the overwhelming number of studies on opinion change focuses on the external or situational determinants (e.g., properties of the source, the message, etc.). Assumptions about internal processes are not often subject to direct examination. For example, considering the variety of standard techniques available it is disconcerting that so few researchers have attempted to determine if in fact dissonance is a noxious drive state (some exceptions being Cottrell \& Wack, 1967; Suedfeld \& Epstein, 1971; Waterman \& Katkin, 1967). Neverthelcss, a more direct scrutiny of private events is recognized as a feasible and fruitful undertaking (Gerard \& Connolley, 1972; McGuire, 1972) of which there already exist several interesting exemplars (see Brock, 1967; Burdick \& Burnes, 1958; Gerard, 1965; Gormly, Gormly, \& Johnson, 1972; Greenwald, 1968; Keating \& Brock, 1974; Steiner, 1966).

The general approach of Brock (1967) and Greenwald (1968) is particularly relevant here. Puzzles by the weak relationship between the extent to which a message is learned and its persuasive impact, Greenwald conjectured that opinion change directly depends on the arguments elicited in the recipient by the message and not so much on those contained in the latter. Hence, independent of the ability to recall what a source advocates, opinion change might be minimal if the target person was not stimulated to think of cogent propositions beyond those contained in the influence attempt; and a boomerang effect could well occur if he happened to imagine novel counterarguments. This line of reasoning quite naturally led to an assessment of argumentative thinking, one which provided considerable support for Greenwald's hypothesis.

Our investigation of group induced shifts in preference has come to a similar point. At present there exist two general explanations for these shifts. One asserts that they are due to interpersonal comparison or normative processes and the other believes that persuasive argumentation or informational processes are critical (see the extensive reviews by Cartwright, 1971; Pruitt, 1971a, b; and Vinokur, 1971; as well as studies by Burnstein \& Vinokur, 1973; Burnstein, Vinokur, \& Trope, 1973). Interpersonal comparison has it that moderate choices have emotional consequences which make them less stable than extreme choices. Consider the Brown (1965) analysis. He says such preferences reflect the person's allegiance to widely held cultural values; individuals who find by comparison that they are relatively moderate are distressed by the implication of moderation, which is, inadequate adherence to cherished standards of conduct, and to display proper adherence they shift toward a more extreme position. The idcas people present to support or to derogate a particular position are explicitly rejected as neither necessary nor sufficient to produce such changes. Persuasive-arguments theory, on the other hand, asserts that knowledge of others' choices has no direct consequences for subsequent revisions in choice. Shifts occur because 
during discussion individuals are exposed to persuasive arguments providing information not available to them prior to making their initial choice.

In testing these two classes of theories we have found considerable support for persuasive-arguments and little or none for interpersonal comparison (see Burnstein, Vinokur, \& Trope, 1973; Burnstein, Vinokur, \& Pichevin, 1974; Vinokur \& Burnstein, 1974). For instance, in an experiment varying knowledge of others' choices independent of argumentation, a reliable main effect was obtained only for the latter. In other words, shifts in choice increased with increasing argumentation; but increasing information about what others had chosen had no general effect (Burnstein, Vinokur, \& Trope, 1973).

While the overall results bode poorly for theories stressing normative processes, internal analysis suggested that individuals with the greatest knowledge about others' choices did tend to revise their initial position in the predicted direction, albeit relatively infrequently. Moreover, a few earlier studies have succeeded in producing similar attenuated shifts when only knowledge of others' choices was provided (e.g., Clark \& Willems, 1969; Teger \& Pruitt, 1967), although several others were not so successful (e.g., Clark, et al., 1971; St. Jean, 1970; Wallach \& Kogan, 1965). On the face of it the effect is a puzzle for the persuasivearguments explanation. How could it be possible for shifts to occur when only the choices of others are known-in the absence of argumentation? To resolve the matter, we speculated as follows:

\footnotetext{
. . . knowledge that others' choices are discrepant from his own may induce the person to reconstruct a line of reasoning which he thinks could have produced such choices. That is to say, knowing others have chosen differently stimulates the person to generate arguments which could explain (and thus would support) their choices. Therefore, according to our conjecture, informing the person that others took a position more extreme than his own does not serve so much to threaten his self-esteem or to legitimize some suppressed yearning but rather induces him to find a reasonable explanation for the difference (Burnstein, Vinokur, $\&$ Trope, 1973, p. 244).
}

The present experiment tests this speculation. Briefly, it consists of three conditions: (I) Individuals learn one another's preferences on a specific decision task and immediately afterward generate arguments in support of each of the alternatives involved in that same task; (II) individuals learn one another's preferences on a specific decision-task and immediately afterward generate arguments in support of each of the alternatives involved in a different task; and (III) individuals know only their own preference on a specific decision-task, they do not know the preference of others, and generate arguments in support of each of the alternatives involved in that same task. If knowledge of the others' choices produces a revision in the person's own preference indirectly, that is, only when such knowledge induces the person to think of arguments explaining 
the others' choices, then a few important effects should be observed. First, shifts in choices will be obtained in Condition I but not in Conditions II and III. In the latter situations the person is prevented from thinking in appropriate fashion, from generating relevant arguments, either because of the nature of the activities he must perform immediately upon being informed of the others' choices (in Condition II) or because he simply does not know what the others have chosen (in Condition III). Secondly, if knowledge of others' choices induces the person to think of reasons why such a course of action might be preferred, then the person will generate more arguments in support of alternatives suggested by the positions of others in Condition I than in Condition III (obviously, only in the former condition can his arguments be informed by what others have chosen). In general this means if individuals shift to a more risky (or cautious) course of action, then we should observe that immediately preceding the shift they will have thought of a greater number of arguments in favor of risk (or caution) than those who do not shift.

On learning others' preferences, no doubt some subjects will find their choice rather risky and some will find their choice rather cautious. Since in the present study only decisions which shift toward risk will be used, we do not expect the initially more risky subjects to shift toward caution. The reason for this is straightforward, although perhaps not totally obvious: Elsewhere it has been shown (Ebbesen \& Bowers, 1974; Silverthorne, 1971; Vinokur \& Burnstein, 1974; Vinokur, Trope, \& Burnstein, 1975) that on decisions which shift toward risk following discussion there are fewer arguments available in favor of the cautious alternative and those available are less cogent than arguments which come to mind in favor of the risky alternative (the converse being true for decisions known to shift toward caution). Recall our hypothesis states that shifts in choice are due to the arguments a person generates to himself upon learning others have chosen differently. If this is true, then subjects who are quite risky and thereby find others are relatively cautious will be able to think of only a few rather unpersuasive arguments in favor of the cautious alternative; on the other hand individuals who are cautious and find others are relatively risky should be capable of coming up with many persuasive arguments in support of the risky course. Therefore, the latter are likely to revise their initial choice but the former are not.

\section{METHOD}

\section{Subjects}

A total of 60 male students from the introductory courses in psychology at the University of Michigan participated in this experiment as part of their course requirement. They were run in 12 5-man groups. 


\section{Materials}

A set of three choice dilemma items were chosen from the standard Choice Dilemma Questionnaire (CDQ). These have been found to yield robust shifts toward risk (items 4, 6 . and 7, Kogan and Wallach, 1964, Appendix E).

Each choice-dilemma was accompanied by the standard instructions to choose--between odds of $1,2,3,4,5,6,7,8,9$, in 10 -the lowest odds of success accepiable in order to recommend trying the uncertain alternative; or, instead, to indicate that this alternative should not be attempted, no matter what the odds. In the latter case, a response is usually scored as 10 . Risk is measured as the odds that are chosen by the subject.

The three items were preceded by the standard instructions and a practice item and assembled in a booklet entitled "Opinion Questionnaire."

In addition to the "Opinion Questionnaire" each subject received two more booklets in the course of the experiment. The first booklet entitled "Consideration Booklet" contained several pages on which pro-risk and pro-caution considerations (arguments) are to be listed by the subjects. At the lop of each page a five-category rating scale was given, This defined for the subject how he should go about assigning weights to the arguments, ranging from "No Weight" (i.e., 0) to "Extreme Weight" (i.e., 4). The rest of the page was divided by horizontal lines into four boxes. In the margin of each box a small space was provided to indicate the weight given to the consideration in the box, and underneath, the instruction to "Circle $\mathrm{L}$ or $\mathrm{H}$ " appeared. Subjects were informed to circle the letter " $L$ " of " $H$ " if the consideration they have listed in the box is basically in support of a rather low probability (i.e.. pro-risk) or a rather high probability (i.e., pro-caution), respectively.

The second booklet entitled "Final Questionnaire" contained instructions and fresh copies of the three items from the "Opinion Questionnaire."

Postexperimental questionnaire: In this questionnaire subjects were asked to:

Please try to recall those two choice-items immediately following which each person in the group announced the probability level he had selected. These were items $A^{1}$ and $B$.

Below you will make certain judgments about how you felt and what you thought while working on these two items. At times you may not be certain about your feelings and thoughts. This is to be expected. Wc would just like you to make the best judgment you can, given what you can recall.

In making this judgment you will evaluate each situation-when you worked on item $A$ and when you worked on item $B$-separately but on the same rating scale. This is done by placing the letter denoting the item at that point on the rating scale which most closely corresponds to how you felt or what you thought while working on the item.

Several statements were then provided for evaluation; each with a 7-point rating scale. The poles were defined as completely true--completely untrue or very much-not at all, whichever was applicable. The statements included:

1. My initial choice was rather different from the initial choices most others made.

2. That there was some difference between my initial choice and the initial choices of others made absolutely no difference to me, i.e., I didn't react at all.

3. I was disturbed by this difference.

4. I was surprised by this difference.

5. I was curious about this difference.

6. I wondered why the others made the choice they did-what they had in mind.

7. I thought of the reasons the others might have had for making their choices.

'The items belonging to the three conditions were alternated from session to session. The actual letters were properly inserted in the questionnaire before each session. 
8. I thought of the reasons for making my own choice.

9. Some new considerations came to mind which I had not thought of earlier.

\section{Procedure and Instructions}

Subjects arriving at the laboratory were seated at small tables in a half circle facing a blackboard and were asked to fill out the "Opinion Questionnaire." After all subjects completed the questionnaire the experimenter distributed the "Consideration Booklet" and asked the subjects to read the cover page which included an explanation of how to list the arguments in the booklet and how to rate them. He then went over the explanation giving hypothetical examples to make sure that all the subjects are clear about the task. Then the "Final Questionnaire" was handed over to the subjects and they were asked to read the following instructions on the cover page:

"In this study we are investigating various conditions that help people in arriving at better decisions. For that reason we will have different procedures in each of the following stages of the experiment and we ask you to follow our instructions carefully."

The experimenter proceeded then with the experimental manipulations which corresponded to the three conditions. Each manipulation involved a separate choice dilemma item. The order of the items was alternated over the experimental sessions.

The first manipulation always consisted of condition III where subjects are not exposed to the choices of the other members and consequently are not engaged in comparison processes. The experimenter asked them to turn to the second item in the "Opinion Questionnaire"' (the first is a practice item) and read the following instructions:

"Now we would like you to reconsider this choice-dilemma again. By thinking it through again you may discover additional relevant considerations. If you do find some new ones, please list these additional considerations in the "Consideration Booklet." Rate each consideration as to how much weight it carries and circle the letter L or H. You are given $4 \mathrm{~min}$ to complete the listing and rating of the new considerations. Only new considerations which had not been considered before should be listed. There is no limit on how few or how many should be listed: all depends on how many come to mind."

At the end of $4 \mathrm{~min}$ the experimenter called for the subjects' attention and read the following instructions:

"Possibly by reconsidering the situation again after having seen it before, you may have a better idea of the kind of decision that you would like to make.

We would like you now to make your final decision on the choice-dilemma in the "Final Questionnaire." Please do not feel bound by what you marked before on the practice booklet. Whether or not you change, or how much you change is not important. What is important is that you reconsider your answer carefully."

After subjects checked their final decision (only $15 \mathrm{sec}$ were allowed) the experimenter proceeded with the next two manipulations which corresponded to conditions I and II. Their order was alternated over the sessions.

In condition II the experimenter asked the subjects to turn to the third item of their "Opinion Questionnaire" and each in turn to read their choice aloud from the questionnaire. These choices were written on the blackboard facing the subjects, and were thus freely and continuously available for inspection. Immediately thereafter subjects were asked to turn to the first (i.e., practice) item in their "Opinion Questionnaire." The experimenter read to them again the above quoted instructions requesting they list their new con- 


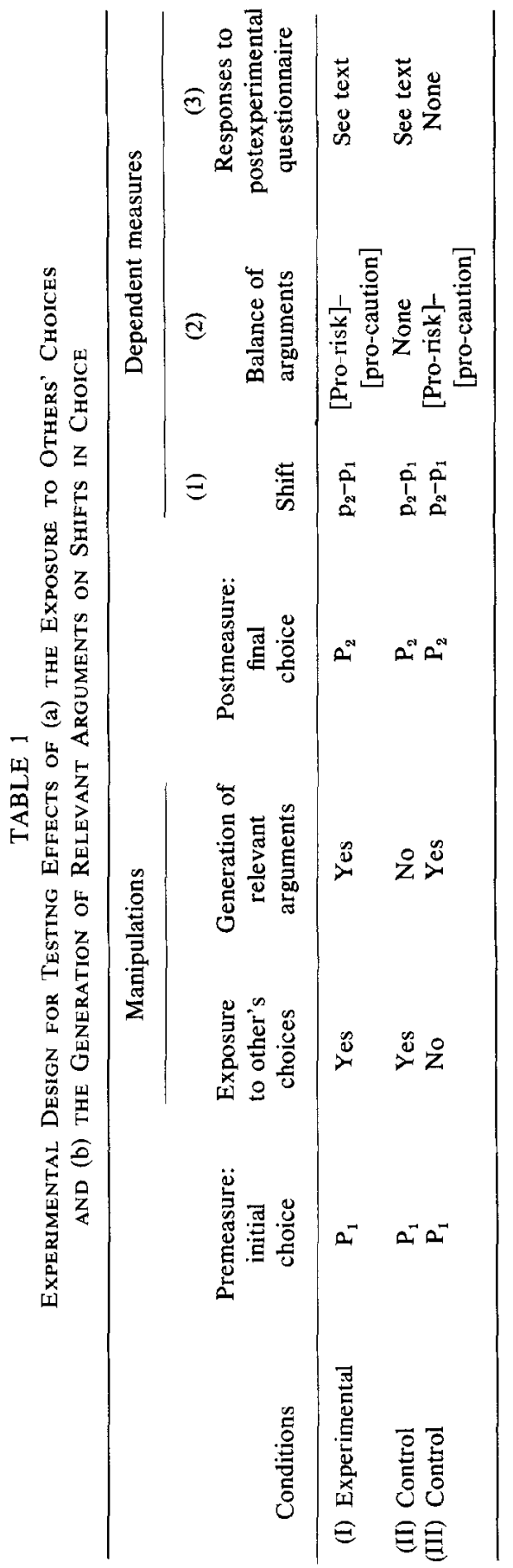


siderations that come to their mind while reexamining this first item. At the end of 4 min the subjects were asked to turn back to the third item in the "Final Questionnaire" (i.e.. same item on which their initial choices are still written on the blackboard) and again the experimenter read the above quoted instructions requesting they make their final choices on that item within the next $15 \mathrm{sec}$. When they were done, the experimenter erased the blackboard.

In condition I, the critical condition, subjects were asked to turn to the fourth item on their "Opinion Questionnaire"; they then read their initial choices to the experimenter and he wrote these on the blackboard. From that point on the experimenter repeated the procedure used for the manipulation in condition III. The experimental design is outlined in Table 1.

Following the last manipulation the subjects were asked to fill out the post experimental questionnaire. When all the questionnaires were completed the purpose of the study was explained and discussed with the subjects.

\section{RESULTS}

\section{Shifts}

The first analysis compared mean shifts in the three conditions. The results are presented in Table 2 .

As hypothesized, the critical manipulation which both (1) exposed each subject to the choices of all others and (2) provided him the opportunity to produce relevant arguments (condition I) yielded substantial and statistically significant shifts toward risk $(\overline{\mathrm{X}}=-.65 ; p<.001)$. The other manipulations, either exposing subjects to the choices of others while precluding relevant argumentative thought (condition II) or providing him with the opportunity of argumentative thinking while withholding information about others' choices (condition III) did not yield reliable shifts.

A one-way analysis of variance with three repeated measures was performed on the shift scores, that is, on the difference between subject's choice before and after the three experimental manipulations. This analysis yielded a statistically significant $F$ ratio $(F(2,22)-9.70 ; p<.001)$. On the basis of the above analysis we examined two orthogonal a priori contrasts: (1) whether the shifts in conditions II and III are different and (2)

TABLE 2

Mean, Standard Deviation, and $t$ Value for Shifts in Choice

\begin{tabular}{ccccc}
\hline Conditions & Mean shift $^{a}$ & $S D$ & $t^{b}$ & $p$ \\
\hline I & -.65 & 0.33 & -6.60 & .001 \\
II & .18 & 0.39 & 1.57 & $\mathrm{~ns}$ \\
III & .02 & 0.62 & .09 & $\mathrm{~ns}$ \\
\hline
\end{tabular}

${ }^{a}$ The values denote odds in 10 . Negative value denotes shifts toward greater risk, i.e., lower probability.

${ }^{b}$ All tests are correlated two-tail $t$ tests based on $n=12$ (i.e., groups). 
whether the shifts in condition I are different than the shifts in condition II and III combined.

For the first contrast, the analysis yielded a statistically nonsignificant $F$ ratio $(F(1,22)<1)$ indicating that the mean shifts in conditions II and III do not differ. For the second contrast, the analysis yielded a statistically significant $F$ ratio $(F(1,22)=18.66 ; p<.001)$ demonstrating that the mean shift in our critical condition (I) is reliably greater than those in the other conditions (II and III).

\section{Balance of Arguments}

Note that in the past, descriptions of the informational processes assumed to cause shifts in choice focused on the actual argumentation taking place during group discussion. This experiment, however, deals with the effects of internal argumentation stimulated by knowledge of others' choice. The concern here is with self-persuasion. Specifically, it is hypothesized that the shifts demonstrated in condition I are the result of arguments that come to mind through exposure to the positions of others. In addition to demonstrating that the opportunity to think about what others chose leads to shifts, our hypothesis requires that the content of these thoughts be analyzed. To this end, the number of pro-risk and pro-caution arguments were summed separately for each subject, as were the weights given to these arguments. The mean total weight and mean number of pro-risk and pro-caution arguments are presented in Table 3.

As predicted, in condition I the number of pro-risk arguments as well as their weight is significantly larger than the number and the weight of the pro-caution arguments $(p<.05)$. This effect does not obtain in condition III. Moreover, although, the number and the weight of pro-caution

TABLE 3

Mean Total Weight, Mean Number of Pro-Risk and Pro-Caution ARguments, and Mean Balance of ARguments

\begin{tabular}{|c|c|c|c|c|c|c|}
\hline \multicolumn{3}{|c|}{$\begin{array}{l}\text { Pro-risk arguments } \\
\text { (1) }\end{array}$} & \multicolumn{2}{|c|}{$\begin{array}{l}\text { Pro-caution } \\
\text { arguments } \\
\text { (2) }\end{array}$} & \multicolumn{2}{|c|}{$\begin{array}{l}\text { Balance of } \\
\text { arguments } \\
\text { (2)-(1) }\end{array}$} \\
\hline Conditions & Weight & Number & Weight & Number & Weight & Number \\
\hline I & 4.03 & 1.45 & 2.73 & 0.98 & $-1.30^{*}$ & $-0.47^{*}$ \\
\hline III & 3.10 & 1.08 & 2.71 & 0.92 & -0.38 & -0.17 \\
\hline I-III & $0.93^{*}$ & $0.37^{* *}$ & 0.02 & 0.06 & -.92 & -.30 \\
\hline
\end{tabular}

Note: All tests are two-tail correlated $t$ tests based on $n=12$ (i.e., Groups).

${ }^{*} p<.05$.

$* * p<.01$. 
arguments are about the same in both conditions, the number and the weight of pro-risk arguments are significantly larger in condition I than in condition III ( $p<.01$ and $p<.05$, respectively).

Finally, if the shifts in condition I are indeed the result of argumentative thinking, then they should correlate with the balance of weighted pro-risk to weighted pro-caution arguments across subjects. The product moment correlation between shifts and the balance of weighted arguments was thus computed for condition I as well as for condition III. A correlation of .30 was obtained for condition I, statistically significant at the .05 level, and a correlation of .12 for condition III, statistically insignificant. This is a rather important finding, demonstrating that relevant arguments which are triggered by exposure to others' choices do in fact mediate shifts in choice.

Responses to the postexperimental questionnaire. First, it is interesting to observe that in condition I subjects who deny that the difference between their own initial choice and the choices of others made no difference for them (Q. 2)-implying it did-tended to be disturbed (Q. 3) and curious $(\mathrm{Q} .5)$ about the difference $(r=.41 ; p<.01 ; r=.31$; $p<.05$, respectively), and to wonder about the reasons others might have had for making their choice (Q. $7: r=.40, p<.01)$. Note that these subjects did not become concerned and think of the reasons for making their own choices (Q. 8: $r=0.00$ ), which suggests that exposure to others' CDQ choices does not make one defensive about his own position. Rather, it stimulates curiosity and leads the person to consider why others chose the way they did.

Consistent with the above results we found also that subjects who thought of the reasons the others might have had for their choices $(Q .7)$ and who indicated that new considerations came to mind (Q. 9) produced a greater number of, as well as more cogent (i.e., given greater weight) pro-risk arguments ( $r=.25$ and .28 , respectively; $p<.05$ for both). Finally subjects who thought about reasons others might have had for their choices (Q. 7) indeed tended to shift toward greater risk $(r=.28, p<.05)$.

\section{DISCUSSION}

Persuasive-arguments theory asserts that knowledge of others' choices is neither necessary nor sufficient for the occurrence of shifts in preference. Rather, shifts are due to the sharing of arguments for a particular course of action during group discussion, arguments which were only partially available to members prior to said discussion (see a more detailed presentation in Burnstein \& Vinokur, 1973; and especially in Vinokur \& Burnstein, 1974). Although past research lends considerably greater support to this point of view than to those based on interpersonal comparison processes, there did exist a few embarrassing studies-ones 
in which knowledge of others' choices alone seemed to produce shifts, albeit attenuated ones. To handle this kind of effect it was conjectured that information about what others have chosen stimulates the person to generate a line of reasoning or argumentation which would explain why these people chose as they did. This means that knowledge about others' preferences can be a sufficient condition for revising preferences to the extent that it leads one to think of arguments in support of the courses of action others have selected, arguments which previously had not come to mind. The present study strongly supports this conjecture. Shifts in choice occurred in the absence of group discussion only when individuals knew and thought about what others had chosen. Moreover, the extent to which they thought of reasons for others' choices determined the extent to which they revised their own choice.

Perhaps equally important, the individual is aware of his feelings and thoughts prior to the shift and this state of mind closely corresponds to that which would be expected on the basis of persuasive-arguments theory. Thus, the person was puzzled about the difference between his own and others' preferences, and mulled over the reasons for the latter (not reasons supporting his own position). Indeed, the more the person reports thinking of why others chose as they did the more he shifts toward their choice.

In the face of these findings as well as those from other recent studies (e.g., Burnstein, Vinokur, \& Trope, 1973; Burnstein, Vinokur, \& Pichevin, 1974; Myers \& Lamm, in press; St. Jean, 1970, 1973) it becomes increasingly difficult to believe that the emotional consequences of interpersonal comparison-embarassment, loss in self-esteem, etc.-play much if any role in choice-shift or polarization phenomena. Instead it may be more useful to view such revisions of opinion as the result of intraand interpersonal information processing similar to that which takes place in group or individual problem solving and in attitude change. And knowledge that others have different preferences-engaging in interpersonal comparisons-may be one condition for stimulating this kind of thinking. That is to say, when choosing, the person weighs what he knows about the alternatives at hand (the relative importance of reasons or arguments for selecting one over the others, etc.), then, based on this knowledge, he makes some inferences about their relative value, and eventually, he chooses the alternative which appears most desirable, proper, or correct. Analogously, when a group decides among (or merely discusses) these alternatives, in essence it infers relative desirability, propriety, or correctness by jointly evaluating the arguments in its possession. Thus, discussion leads each individual to reweigh his old reasons for selecting a particular course and to consider new reasons others have introduced, which process is often followed by a revision in choice.

More specifically, our findings demonstrate that the reweighing of old 
arguments and the introducing of new ones also may be occasioned by others indirectly, to the extent that a person is induced to generate new arguments explaining (and thus supporting) their choices. It may be conjectured, as does Greenwald (1968), that creating and reweighing arguments perhaps constitute the necessary and sufficient conditions for revisions of opinion and choice. If so, effort should now go toward discovering the nature of such argumentation.

\section{REFERENCES}

Barnlund, D. C. A comparative study of individual, majority, and group judgment. Journal of Abnormal and Social Psychology, 1959, 58, 55-60.

Brock, T. C. Communication discrepancy and intent to persuade as determinants of counterargument production. Journal of Experimental Social Psychology, 1967, 3, 296-309.

Brown, R. Social psychology. New York: Free Press of Glencoe, 1965.

Burdick, H. A. \& Burnes, A. J. A test of "strain toward symmetry" theories. Journal of Abnormal and Social Psychology, 1958, 57, 367-369.

Burnstein, E. \& Vinokur, A. Testing two classes of theories about group induced shifts in individual choice. Journal of Experimental Social Psychology, 1973, 9, 123-137.

Burnstein, E., Vinokur, A., \& Trope, Y. Interpersonal comparison versus persuasive argumentation: A more direct test of alternative explanations for group induced shifts in individual choice. Journal of Experimental Social Psychology, 1973, 9, 236-245.

Burnstein, E., Vinokur, A., \& Pichevin, M. F. What do differences between own, admired, and attributed choices have to do with group induced shifts in choice? Journal of Experimental Social Psychology, 1974, 10, 428-443.

Cartwright, D. Risk taking by individuals and groups: an assessment of research employing choice dilemmas. Journal of Personality and Social Psychology, 1971, 20, 361-378.

Clark, R. D. \& Willems, E. P. Where is the risky shift. Journal of Personality and Social Psychology, 1969, 13, 215-221.

Clark, R. D., Crockett, W. II., \& Archer, R. L. Risk as value hypothesis: The relationship between perception of self, others and the risky shift. Journal of Personality and Social Psychology, 1971, 20, 425-429.

Cottrell, N. B. \& Wack, D. L. Energizing effects of cognitive dissonance upon dominant and subordinate responses. Journal of Personality and Social Psychology, 1967, 6, 132-138.

Deutsch, M., \& Gerard, H. G. A study of informational social influences upon individual judgment. Journal of Abnormal and Social Psychology, 1965, 51, 629-636.

Doise, W. Intergroup relations and polarization of individual and collective judgments. Journal of Personality and Social Psychology, 1969, 12, 136-143.

Ebbesen, E. B. \& Bowers, R. J. Proportion of risky to conservative arguments in a group discussion and choice shift. Journal of Personality and Social Psychology, 1974, 29, 316-327.

Gerard, H. B. Deviation, conformity, and commitment. In I. D. Steiner and J. Fishbein (Eds.), Current studies in social psychology. New York: Holt, Rinehart \& Winston, 1965. Pp. 263-277.

Gerard, H. B. \& Connolley, E. S. Conformity, In C. G. McClintock (Ed.), Experimental social psychology. New York: Holt, Rinehart \& Winston, 1972. Pp. 237-263.

Gormly, J., Gormly, A., \& Johnson, C. Consistency of sociobehavioral responses to interpersonal disagreement. Journal of Personality and Social Psychology, 1972, 24, 221-224. 
Gouge, C. \& Fraser, C. A further demonstration of group polarization. European Journal of Social Psychology, 1972, 2, 95-97.

Greenwald, A. G. Cognitive learning, cognitive response to persuasion, and attitude change. In A. G. Greenwald, T. C. Brock \& T. M. Ostrom (Eds.), Psychological foundations of attitudes. New York: Academic Press, 1968.

Hall, E., Mouton, J., \& Blake, R. Group problem solving effectiveness under conditions of pooling vs. interaction. Journal of Social Psychology, 1963, 59, 147-157.

Keating, J. P. \& Brock, T. C. Acceptance of persuasion and the inhibition of counterargumentation under various distraction tasks. Journal of Experimental Soctal Psychology, 1974, 10, 301-309.

Kelley, H. H. \& Thibaut, J. W. Group problem solving. In G. Lindzey \& E. Aronson (Eds.), Handbook of social psychology, Vol. IV (2nd ed.). Cambridge, Mass.: Addison-Wesley, 1969.

Kogan, N. \& Wallach, M. A. Risk taking: A study in cognition and personality. New York: Holt, Rinehart \& Winston, 1964.

Lambert, R. Extrémisation du comportement de prise de risque en groupe et modèle majoritaire. Psychologie Francaise, 1969, 14, 113-125.

Lambert, R. Extrémisation due risque en groupe. Journal de la Societe de Statistique de Paris, 1971, 112, 11-22.

Lorge, I. \& Solomon, H. Two models of group behavior in the solution of eureka-type problems. Psychometrika, 1955, 20, 139-148.

McGuire, W. J. Attitude change: the information processing paradigm. In C. G. McClintock (Ed.). Experimental social psychology. New York: Holt, Rinehart \& Winston, 1972. Pp. 108-141.

Moscovici, S. \& Zavalloni, M. The group as a polarizer of attitudes. Journal of Personality and Social Psychology, 1969, 12, 125-135.

Myers, D. G. \& Bishop, G. D. Discussion effects on racial attitudes. Science, 1970, 169, 778-779.

Myers, D. G. \& Bishop, G. D. Enhancement of dominant attitudes in group discussion. Journal of Personality and Social Psychology, 1971, 20, 386-391.

Myers, D. G. \& Lamm, H. The group polarization phenomenon. Psychological Bulletin, in press.

Pruitt, D. G. Choice shifts in group discussion: An introductory review. Journal of Personality and Social Psychology, 1971, 20, 339-360. (a)

Pruitt, D. G. Conclusions: toward an understanding of choice shifts in group discussion. Journal of Personality and Social Psychology, 1971, 20, 495-510. (b)

Silverthome, C. P. Informational input and the group shift phenomenon in risk taking. Journal of Personality and Social Psychology, 1971, 20, 456-461.

Steiner. I. D. Personality and the resolution of interpersonal disagreements. In B. Maher (Ed.), Progress in experimental personality research. Vol. 3. New York: Academic Press, 1966. Pp. 165-239.

Steiner, I. D. Group process and productivity. New York: Academic Press, 1972.

St. Jean, R. Reformulation of the value hypothesis in group risk taking. Proceedings of the 78th Annual Convention of the American Psychological Association, 1970, 5, 339-340.

St. Jean, R. Relevant arguments, group membership, and the shift to risk. Unpublished manuscript, University of Prince Edward Island, 1973.

Suedfeld, P. \& Epstein, Y. M. Where is the " $D$ " in dissonance? Journal of Personality, $1971,39,178-188$.

Teger, A. I. \& Pruitt, D. G. Components of group risk taking. Journal of Experimental Social Psychology, 1967, 3, 189-205.

Thomas, E. J. \& Fink, C. F. Models of group problem solving. Journal of Abnormal and Social Psychology, 1961, 63, 53-63. 
Thorndike, R. L. The effect of discussion upon the correctness of group decisions, when the factor of majority is allowed for. Journal of Social Psychology, 1938, 9, 343-362. (a)

Thorndike, R. L. On what type of task will a group do well? Journal of Abnormal and Social Psychology, 1938, 33, 409-413. (b)

Vinokur, A. Review and theoretical analysis of the effects of group processes upon individual and group decisions involving risk. Psychological Bulletin, 1971, 76, 231-250.

Vinokur, A. \& Burnstein, E. The effects of partially shared persuasive arguments on group induced shifts: A group problem solving approach. Journal of Personality and Social Psychology, 1974, 29, 305-315.

Vinokur, A., Trope, Y., \& Burnstein, E. A decision making analysis of persuasive argumentation and the choice-shift effect. Journal of Experimental Social Psychology, $1975,11,127-148$.

Wallach, M. A. \& Kogan, N. The roles of information, discussion and consensus in group risk taking. Journal of Experimental Social Psychology, 1965, 1, 1-19.

Waterman, C. K. \& Katkin, E. S. Energizing (dynamogenic) effect of cognitive dissonance on task performance. Journal of Personality and Social Psychology, 1967, 6, 126-131.

(Received May 8, 1974) 